\title{
Teaching Basic Probability In Undergraduate Statistics Or Management Science Courses
}

Jaideep T. Naidu, Philadelphia University, USA

John F. Sanford, Professor Emeritus, Philadelphia University, USA

\begin{abstract}
Standard textbooks in core Statistics and Management Science classes present various examples to introduce basic probability concepts to undergraduate business students. These include tossing of a coin, throwing a die, and examples of that nature. While these are good examples to introduce basic probability, we use improvised versions of Russian Roulette and found these to be very effective in communicating important concepts in probability to our business school students. We use these modified versions of Russian Roulette to communicate concepts such as dependent event, joint probabilities and the value of information using Bayes' law. The students understand and enjoy these examples and the class participation has been higher than usual.
\end{abstract}

Keywords: Probability; Dependent Event; Joint Probability

\section{INTRODUCTION AND OVERVIEW}

\section{Probability: A Definition}

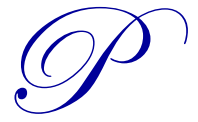

robability is the measure of the likelihood that an event will occur. Probability is a numerical value between 0 and 1 that measures the likelihood that a particular event will occur. The value 0 indicates impossibility and 1 indicates certainty. The higher the probability of an event, the more certain we are that the event will occur.

\section{Applications of Probability}

Probability theory has various applications and used in business applications, weather forecasting, risk assessment, financial markets, sports, reliability theory in product design, presidential elections, healthcare, engineering applications, biology, and so on. Because of the importance of probability theory in business, engineering and healthcare applications in general, textbooks in Statistics and Management Science devote a complete chapter to introduce probability theory.

\section{An Introduction to our approach of teaching Basic Probability}

Standard textbooks in Statistics or Management Sciences courses contain various examples to introduce basic probability concepts to undergraduate business students. These examples include tossing of a coin, throwing a die, picking a marble of a certain color from a bunch of marbles of different colors among other examples. While these are certainly good examples to introduce basic probability to business school students, we use modified versions of Russian Roulette and found these examples to be very effective in communicating some important concepts in probability. We use this example to introduce concepts like dependent event, joint probabilities and the value of information using Bayes' law. For the sake of brevity, we provide list only a few textbooks in our references but at the same time making sure that various fields are taken into account. While Lapin (1999), Bowerman, O'Connell and Murphree (2013), and Taylor (2016) cater to business students, Campbell, Machin, and Walters (2007) and 
Montgomery and Runger (2014) cater to students in the Health Sciences and Engineering fields respectively. All of these textbooks devote a separate chapter to introduce and discuss probability theory.

\section{An Understanding of Russian Roulette}

Russian roulette is a deadly game of chance in which a player places a single bullet in a revolver, spins the cylinder, and shoots himself. This game is supposed to have originated in Russia. Because only one chamber is loaded, the player has a one in six chance of being shot - assuming that a revolver can hold six bullets. This probability concept learned from Russian Roulette is very elementary as students see immediately that the chance is one in six or 1/6. However, it is this basic principle that motivated us to increase the complexity of this game by using more bullets and sequencing them in different ways in a standard revolver that holds 6 bullets.

In the next section, we present different modifications of Russian Roulette that we use in the classroom to communicate various fundamental concepts in probability theory.

\section{MODIFIED VERSIONS OF RUSSIAN ROULETTE USED FOR TEACHING}

Modification 1. We start with a simple modification of the Russian Roulette as shown in Figure 1 below. Note that the bullets (black circles) are placed in alternate chambers and the white circles denote empty chambers.

Figure 1.

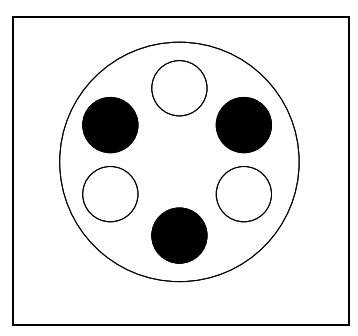

Before targeting the first person, the cylinder is spun. The probability of target 1 dying is thus $3 / 6$ i.e., $50 \%$. Assuming the first target does not die (indicating there was no bullet in that chamber), the students are posed with the question of the probability of the second target dying. The alert students almost always ask if the cylinder is spun again before targeting the second person. This is because their response depends on this fact. Due to the sequencing of the bullets, it is obvious that the second target will be dead if the cylinder is not spun again (as there is a bullet in the next chamber). If the cylinder is spun, then the probability is again $50 \%$ as there are still 3 bullets and 6 chambers. If the second person dies, then there is only a $2 / 6$ chance of the third person dying (if the cylinder is spun). The students are quick to grasp the fact that their response depends on two pieces of information: (i) if the cylinder is spun or not; and (ii) the number of bullets remaining. Thus, they appreciate that this is an excellent example to understand dependent event probability.

Modification 2. We now look at another simple variation of the Russian Roulette where bullets are placed randomly in the chambers as shown in Figure 2 below.

Figure 2

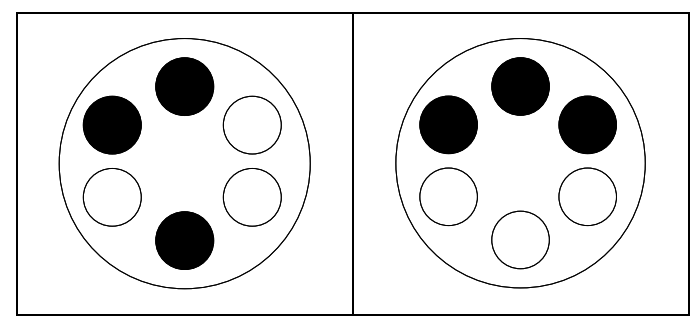


At first glance, it may seem like this is not different from Figure 1. While it may be true that there are still only 3 bullets and 6 chambers in Figure 2, the important point to be noted is that these bullets are placed randomly and not in any particular sequence. In other words, Figure 2 may well look like a case where there are 2 bullets in consecutive chambers but that feature is a random occurrence. The key point that the students need to understand is that bullets are placed randomly. To avoid confusion, we choose not to illustrate this and instead we just state this modification in words. Since bullets are placed randomly (i.e., in an unknown sequence), one will not be able to predict the outcome of the third shot even after two shots are fired in this modification.

Before targeting the first person, the cylinder is spun. The probability of target 1 dying is thus $3 / 6$ i.e., $50 \%$. Assuming the first target does not die (indicating there was no bullet in that chamber), the students are posed with the question of the probability of the second target dying. The students usually state correctly that there is a $3 / 5$ chance of the second person dying if cylinder is not spun at this time (it is obvious that the probability is still $50 \%$ if the cylinder was spun before targeting the second person). Now if the second person dies, then the correct probability of the third person dying will be $2 / 4$ if the cylinder is not spun and $2 / 6$ otherwise. Once again, the students understand that their responses depend on whether the cylinder is spun or not; and the number of bullets remaining.

Modification 3. Our third and last modification is based on a well-known Bollywood film called "Sholay" which is loosely based on Akira Kurosawa's 1954 film "Seven Samurai" and also drew Hollywood films like "Butch Cassidy and the Sundance Kid". In this Bollywood film "Sholay", Gabbar Singh (the bad guy) made sure there were only three bullets in consecutive chambers (as shown in Figure 3 below) and then he spins it before the first man was targeted. No one knew which chamber had a bullet. There was fear in the first man's eyes. When he escaped, the second man looked even more scared but even he escapes (indicating the chamber was empty again). When it was the third man's turn, he was completely terrified. While watching this film, it was easy to understand that the chance of death was increasing as Gabbar Singh went from his first target to his third.

\section{Figure 3}

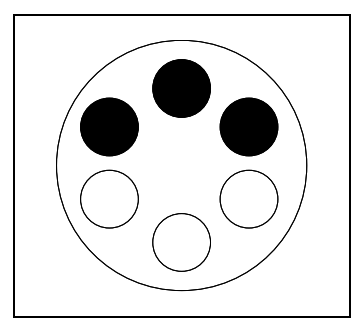

We examine Modification 3 for the following reasons.

(a) The concept of Russian Roulette seems to really engage the students.

(b) The Probability Tree below (Figure 4) offers a unique opportunity to find probabilities and joint probabilities through examination of possible configurations.

(c) It provides an opportunity to dramatize the value of information and Bayes Law.

Let us designate the targets, in order, as $\mathrm{A}, \mathrm{B}$, and $\mathrm{C}$. Then $\mathrm{AD}$ represents the sad demise of target $\mathrm{A}$ and $\mathrm{AL}$ represents the situation where target $\mathrm{A}$ lives.

We ask the class to find the probability that the first target will live after the first shot.

$\mathrm{P}(\mathrm{AL})=1 / 2$. This is pretty easily arrived at by counting bullets.

Then what is the apriori probability that A will live and B will die? That is, before the trigger is pulled, what is the probability

$$
\mathrm{P}(\mathrm{AL} \cap \mathrm{BD})=\text { ? }
$$


The class should see that there is only one starting position where A lives and B dies. So

$$
\mathrm{P}(\mathrm{AL} \cap \mathrm{BD})=1 / 6
$$

Now assume that the trigger has been pulled once and we see that A lives. What is the conditional probability that B will die?

$$
\mathrm{P}(\mathrm{BD} \mid \mathrm{AL})=?
$$

Students are asked to look at the diagram and see how many situations exist where A will live. There are three. Of the three how many would lead to B not living? There is only one. So

$$
\mathrm{P}(\mathrm{BD} \mid \mathrm{AL})=1 / 3
$$

Here is the value of information. The probability was $1 / 6$ but now it is $1 / 3$.

Now Bayes law states that

$$
\mathrm{P}(\mathrm{BD} \mid \mathrm{AL})=\mathrm{P}(\mathrm{AL} \cap \mathrm{BD}) / \mathrm{P}(\mathrm{AL})=(1 / 6) /(1 / 2)=1 / 3
$$

The instructor could ask students to find other probabilities. For example:

$\mathrm{P}(\mathrm{CL} \mid \mathrm{AL} \cap \mathrm{BL})=\mathrm{P}(\mathrm{AL} \cap \mathrm{BL} \cap \mathrm{CL}) / \mathrm{P}(\mathrm{AL} \cap \mathrm{BL})=(1 / 6) /(1 / 3)=1 / 2$

Figure 4. Probability Tree

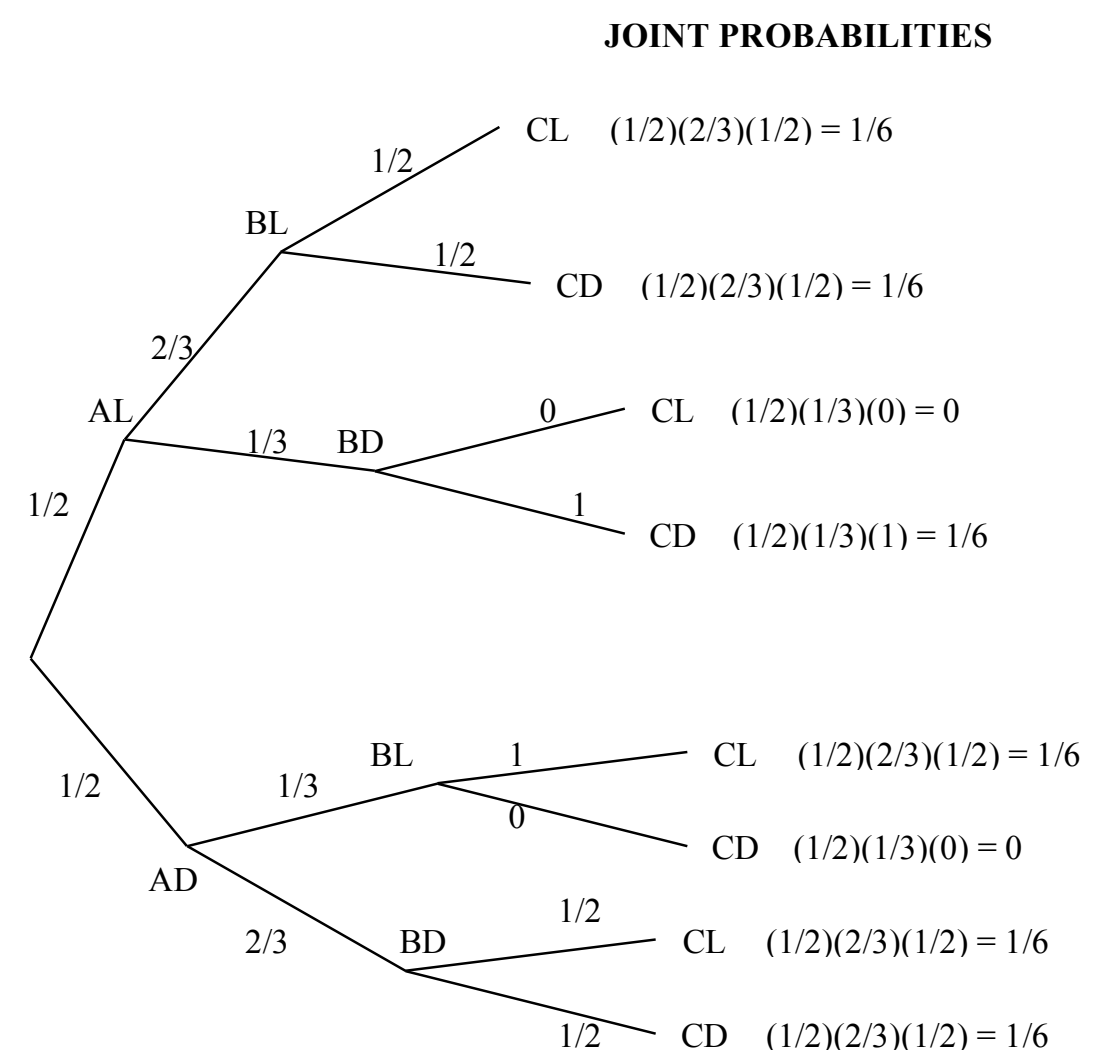


This can be seen from the probability tree too. There are only two situations where A and B both live. Of these only one results in $\mathrm{C}$ living.

Sometimes a probability tree is helpful, but optional. One thing the tree does is to make Bayes' Law more or less obvious. $\mathrm{P}(\mathrm{AL} \cap \mathrm{BD})$ is found on the tree by multiplying $(1 / 2)(1 / 3)=1 / 6$. So what could be more obvious than to find the conditional probability $\mathrm{P}(\mathrm{BD} \mid \mathrm{AL})$ than to divide by the $1 / 2$ that we just used as a multiplier in order to find the conditional probability of $1 / 3$ appearing on the $\mathrm{AL} \rightarrow \mathrm{BD}$ line of the probability tree.

The surprising outcome in the film Sholay was that all three of the bad guy's targets escaped death i.e., $\mathrm{P}(\mathrm{AL} \cap \mathrm{BL}$ $\cap \mathrm{CL})=1 / 6$. What is the probability of such an outcome where all three of his men escaped death? Common sense tells us that there is one and only one starting point that can yield such an outcome and hence it is $1 / 6$. Note that there would have been a completely different set of probability values if Gabbar Singh (the bad guy in the film Sholay) had spun his cylinder after every shot. But probabilities are still conditional. Future probabilities depend on how many bullets are left. So if A lives, the probability of B dying is still $1 / 2$ but if A dies, then the probability that B will die is $2 / 6$ or $1 / 3$.

\section{CONCLUSION}

We present improvised or modified versions of the Russian Roulette to introduce basic probability concepts to our business school students. We found these examples to be very effective in engaging the students as well as increase their understanding of basic probability theory. This teaching style made it easy for the students when we proceeded to solve more difficult cases and problem solving exercises that are directly applicable in the business world. We wish to also state that we let our students know in advance that the Russian Roulette examples are merely to understand basic probability concepts. In our experience, none of the students found this example to be morbid or offensive. As a matter of fact, they found these examples to be very interesting.

\section{AUTHOR BIOGRAPHIES}

Jaideep Naidu is an Associate Professor of Operations Management and Management Science at the School of Business Administration, Philadelphia University. He holds a Ph.D. in Operations Management from The University of Mississippi. His research interests center on machine scheduling problems and higher education. Among other journals, his work has appeared in Journal of the Operational Research Society, Omega - The International Journal of Management Science, International Journal of Operations and Quantitative Management, and American Journal of Business Education.

John Sanford is an Emeritus Professor of Information Systems at Philadelphia University. He holds a Ph.D. in Engineering from Yale University. His teaching interests are in the areas of MIS, Operations Management and Statistics. His research interests include information systems, Data Analysis, and data analysis with Fuzzy Systems. His recent publications are in The International Journal of Teaching and Case Studies and American Journal of Business Education.

\section{REFERENCES}

Lapin, L.L. (1999), Quantitative Methods for Business Decisions with Cases, 6/e, Duxbury Press.

Bowerman, B.L., O’Connell, R.T. and Murphree, E.S. (2013), Business Statistics in Practice, 7/e, McGraw-Hill Irwin, New York, NY.

Taylor, B.W. (2016), Introduction to Management Science, 12/e, Pearson Education Limited.

Campbell, M.J., Machin, D. and Walters, S.J. (2007), Medical Statistics: A Textbook for the Health Sciences, 4/e, Wiley.

Montgomery, D.C. and Runger, G.C. (2014), Applied Statistics and Probability for Engineers, 6/e, Wiley. 


\section{NOTES}

